\title{
A poesia de Chacal na revista O Carioca e no CEP 20.000
}

\author{
Chacal's poetry in the literary magazine O Carioca and at CEP 20.000
}

La poesía de Chacal en la revista O Carioca y en el CEP 20.000

Renata Gonçalves Gomes ${ }^{*}$

\section{Resumo}

Este artigo tem como objetivo principal fazer um levantamento historiográfico da revista $O$ Carioca, bem como trazer à tona questionamentos sobre a poesia contemporânea brasileira a partir do periódico literário O Carioca e da experimentação poética CEP 20.000. Ambos os projetos se desenvolveram nos anos 1990 e evocam uma poética em torno da capital fluminense. Porém, a revista teve apenas cinco números publicados, enquanto que o CEP 20.000 vem até hoje movimentando a cena cultural do Rio de Janeiro. Entre questões que envolvem o contemporâneo, o mercado, poesia e vida, e identidade nacional, este artigo tenta trazer um pouco do que é a poética de um dos poetas mais persistentes da década de 1970 e que vem, até hoje, publicando tanto em livros quanto em periódicos literários.

Palavras-chave: Chacal, Revista O Carioca, CEP 20.000, periódicos, poesia contemporânea brasileira.

\section{Abstract}

This article's primary objective is to provide a historiographic overview of the periodical $O$ Carioca, as well as to shed light on the development of contemporary Brazilian poetry in literary periodicals and poetic experimentations such as Chacal's CEP 20.000. Both projects, O Carioca and CEP 20.000, were developed during the 1990s and evoke a poetics concentrated in the capital of Rio de Janeiro. However, the periodical only published five volumes, whereas CEP 20.000 continues to influence the cultural scene of the city today. Through questions of the contemporary, the literary market, poetry, life and national identity, this article analyzes the poetics of Chacal, one of the most prolific poets of his generation.

Keywords: Chacal, O Carioca literary magazine, periodicals, contemporary Brazilian poetry.

\section{Resumen}

Este estudio tiene como objetivo principal hacer un levantamiento historiográfico de la revista $O$ Carioca, así como llevar a la luz cuestionamientos sobre la poesía contemporánea brasileña a partir del periódico literario $O$ Carioca y de la experimentación poética CEP 20.000. Ambos proyectos se desarrollaron en la década de los noventa y evocan una poética alrededor de la capital fluminense. Sin embargo, la revista tuvo apenas cinco números publicados, mientras que el CEP 20.000 viene agitando hasta hoy el escenario cultural de Rio de Janeiro. Entre cuestiones que involucran lo contemporáneo, el mercado, la poesía, la vida y la identidad nacional, este trabajo intenta aportar al conocimiento sobre la poética de uno de los poetas más persistentes de la década de los setenta y que viene publicando hasta hoy tanto en libros como en periódicos literarios.

Palabras clave: Chacal, revista $O$ Carioca, CEP 20.000, periódicos, poesía contemporánea brasileña.

Este artigo tem como objetivo principal fazer um levantamento historiográfico da revista $O$ Carioca, bem como trazer à tona questionamentos sobre a poesia contemporânea brasileira a partir do periódico literário $O$ Carioca e da experimentação poética CEP 20.000, ambos coordenados por Chacal. Dessa forma, esse artigo apresenta dados e análises de ambos os projetos de Chacal a fim de entender a cena da poesia carioca a partir da movimentação cultural da capital fluminense projetada por Chacal. Primeiramente, revelo alguns dados da revista O Carioca e faço

\footnotetext{
* Doutora em literaturas em língua inglesa e professora da Universidade Federal da Paraíba, João Pessoa, PB, Brasil. (D) orcid.org/00000002-8593-5088. E-mail: gomex10@hotmail.com
} 
questionamentos analíticos. Num segundo momento, o CEP 20.000 é trazido como objeto de estudo e de análise para a compreensão da poética de Chacal e seus movimentos de promoção à cultura na cidade do Rio de Janeiro.

A revista poético-cultural O Carioca, editada em seus cinco números entre 1995 e 1998 pelo poeta Chacal, traz em seu nome e em seus colaboradores uma relação estreita tanto com a cidade quanto com os movimentos culturais do Rio de Janeiro. Com colaboradores entre poetas e artistas já consagrados e aqueles sem inserção em qualquer mídia ou distribuição de suas obras na época, a revista se tornou o espaço de publicação para um grande grupo de artistas que, de uma forma ou de outra, aos trancos e barrancos - ou nem tanto -, movimentavam parte do meio cultural da cidade. A temática da revista está para além de buscar uma vanguarda poética e estabelecer uma conexão entre a estética e a forma da poesia de seus colaboradores, ela procura a consolidação de uma movimentação cultural carioca inquietante - o carioca, neste sentido, quer dizer tanto aquele que nasceu na cidade do Rio de Janeiro como também aquele que constrói uma poética em torno da experiência na capital fluminense.

Com uma tiragem média de dois mil exemplares por edição, um formato que lembra a antiga e extinta revista Senhor mista com a tropicalista Navilouca e as dimensões de $25 \mathrm{~cm}$ por $34 \mathrm{~cm}$, $O$ Carioca se autodefinia não só por seu nome, mas também pelo mote que a acompanhou nas cinco edições: "Revista de Arte e Cultura".

O maior investimento no periódico veio da Prefeitura do Rio de Janeiro através do RioArte, que era um órgão da Secretaria Municipal de Cultura. O RioArte viabilizava, através da Lei de Incentivo à Cultura, a abertura de editais para que os contemplados conseguissem financiadores para projetos. Em um dos anúncios da edição número dois, na parte interna da contracapa, O Carioca deixava bem claro quem era sua principal parceira, a Prefeitura: "uns criam/outros dirigem/uns produzem/outros aplaudem/cada um faz sua parte:/quem inventa é tu/ quem apóia é o RioArte" (O Carioca, 1996a, p. 4), num misto entre publicidade e poema.

Bernardo Vilhena - que também era editor do periódico e parceiro de Chacal da época do grupo Nuvem Cigana - logo conseguiu um contrato com o Jornal do Brasil para a impressão da revista, em troca de contribuições de crônicas semanais dos editores da O Carioca para o jornal, numa relação mais para escambo de serviços do que para mecenas/artistas. No único anúncio do Jornal do Brasil na revista, na parte interior da capa do terceiro número, havia: “O JB escreve com todas as letras que o carioca pensa" (O Carioca, 1996b, p. 2). Era assim. Até mesmo nos anúncios dos investidores havia uma postura e incorporação da capital fluminense que identificava tanto o periódico quanto os anunciantes. Além de Chacal, que foi editor chefe durante toda a existência da revista, Bernardo Vilhena e Waly Salomão também dividiram o editorial nos números dois, três ${ }^{1}$ e quatro, e consequentemente, dividiriam também as crônicas no JB. ${ }^{2}$

A disparidade do grupo do conselho editorial é grande: Waly Salomão, Fausto Fawcett, Carlito Azevedo, Fernanda Abreu, Antônio Carlos Secchin, Barrão, entre outros. A junção de poetas, músicos e artistas plásticos no conselho editorial é sintoma do hibridismo pulsante da revista, que procura ser o reflexo do que está acontecendo no meio cultural da capital fluminense, e busca a consolidação dos artistas veteranos e o lançamento de novos artistas. Há em O Carioca uma postura diferente da adotada, por exemplo, no Almanaque Biotônico Vitalidade, ${ }^{3}$ periódico que foi confeccionado por um grupo, um selo editorial, o Nuvem Cigana.

\footnotetext{
${ }^{1}$ Única edição da qual o artista plástico Raul Mourão participou como editor.

${ }^{2}$ A busca por essas crônicas no Jornal do Brasil não pode ser concluída. Porém, é importante dizer que o sistema de busca do periódico é feito a partir da data de publicação através do portal (http://www.jb.com.br/paginas/news-archive/), como me foi informado por email pelas responsáveis do grupo de administração em pesquisa do $J B$, Eliane Loss e Ana Paula Amorim. Ou seja, além de não ter disponíveis online todos os exemplares do $J B$, a busca pelas crônicas deveria ser feita por suas datas de publicação, mas essa informação não existe. Segundo Chacal, "Bernardo conseguiu uma permuta com o Jornal do Brasil, que imprimia a revista em sua gráfica em troca de crônicas semanais dos editores. Ganhávamos duplamente: com a impressão da revista e a exposição na mídia" (Chacal, 2010, p. 179), revelando assim, sua estratégia de mercado.

${ }^{3}$ Para mais informações sobre o periódico, ler o artigo: "Almanaque Biotônico Vitalidade e as Artimanhas: a contracultura engarrafada no Brasil", de Renata Gonçalves Gomes (2015).
} 
Essa ausência de grupo é uma referência das colaborações de Chacal nos periódicos mais recentes: do grupo Nuvem Cigana apenas Chacal mantém-se publicando poesia.

O periódico editado por Chacal tem um tom de amizade, camaradagem: uma revista feita por amigos e para amigos. Esse tom de amizade que $O$ Carioca transmite ao leitor veio a mim, principalmente, a partir de uma dificuldade na indexação de seus fascículos. A dificuldade apareceu quando percebi que havia um grande número de colaboradores ou de autores citados que ainda não existiam na base de dados, ou seja, não circulavam em nenhum outro periódico já indexado do acervo do Núcleo de Estudos Literários e Culturais (NELIC). ${ }^{4}$ Até então, situação corriqueira para uma indexação, já que os colaboradores variam bastante de periódico para periódico de cada época. Porém, por esses colaboradores/autores citados terem nomes demasiadamente comuns, muitas vezes sem sobrenome ou apenas assinados com apelidos, e ainda, de pouca circulação fora do meio carioca em que se sustentam, a busca pela identidade de alguns desses nomes tornou-se quase impossível. Nesse caso, a leitura das memórias de Chacal como Posto 9, Uma história à margem e longos depoimentos como as do livro Nuvem cigana, Poesia $\mathcal{E}$ delírio no Rio dos anos 70, fizeram com que alguns "apelidos" fossem reconhecidos. É o caso de Barrão, artista plástico que colaborou não só em $O$ Carioca, mas também em algumas capas de livros de Chacal, como em Tontas coisas (em que aparece creditado como Jorge Barrão), A vida é curta pra ser pequena e Uma história à margem. Porém, apenas a leitura da revista não identifica esses colaboradores, não há preocupação em tornar esses nomes mais acessíveis ao leitor fora do meio cultural carioca. É o caso de Gibi e de Nanico, ambos poetas quase escondidos por seus próprios nomes-apelidos, como, provavelmente, aconteceria com Chacal, caso sua assinatura não tivesse sido tão publicada em livros e em periódicos e sua poética não tivesse sido tão debatida e lida desde a década de 1970.

Nas entrevistas, principalmente, o tom de descontração é sempre muito visível, pois tanto o entrevistado quanto os entrevistadores deixam claro o laço afetivo e de amizade. Durante as conversas, pessoas conhecidas em comum tanto do entrevistado quanto dos entrevistadores ficam soltas sem seus primeiros nomes ou sobrenomes. Algumas vezes, os nomes são explicados durante a entrevista, mas não para o leitor, e sim, para o próprio entrevistador, para que ele os reconheça e mantenha o fluxo da conversa. Como é o caso da entrevista de Luis Melodia feita por Chacal, Bernardo Vilhena, Adriana Pittigliani, Álvaro Costa e Silva e Waly Salomão. Nomes como Paulinho da Mariquinha, Bené, Adílson, Naô e Tineca passam pelo texto da entrevista sem grandes explicações de suas procedências ou carreiras artísticas. O mesmo acontece na entrevista de Fernanda Abreu, no número 3 da revista, quando cita nomes como Graziela, Carlos, Gringo, e outros, sem que haja parênteses no corpo do texto trazendo o sobrenome ou nome da pessoa citada.

Por isso, alguns colaboradores e autores citados não foram identificados com um possível conjunto de obras ou ainda com seus nomes completos, mas mesmo assim foram inseridos na base de dados, pois esse anonimato faz parte de uma das principais características da revista e de seus colaboradores. E uma dúvida foi lançada sobre esses nomes: seriam apenas amigoscolaboradores que não teriam o texto - seja ele em forma de ensaio, poesia ou artes plásticas como prática profissional e sim como brincadeira a ser exposta na "revista do amigo"? Ou seria essa uma prática amadora de se fazer um periódico literário? Esse tom de descontração, essa revista de/para amigos traz a questão do anonimato que aparece logo na figura do editor-chefe da revista: Chacal, que mantém seu codinome desde seu segundo livro mimeografado. Há uma identificação com a "turma" que movimenta o meio cultural da capital fluminense, feita antes por amigos do que por sócios.

Talvez seja a partir dessa "curtição total", de um fazer a revista para nós mesmos, que anos depois com um pouco de pesar, porém sem perder a piada, Chacal ressalta a necessidade de terse criado um público-alvo para a $O$ Carioca, algo que parece não ter sido pensado na época.

\footnotetext{
${ }^{4}$ Parte deste artigo é resultado da indexação da revista $O$ Carioca feita em 2010 por mim na base de dados do NELIC da Universidade Federal de Santa Catarina, coordenado pela dra. Maria Lúcia de Barros Camargo.
} 
Tentamos mas não conseguimos. Foi uma aventura que durou dois anos e cinco números. Nada mau para o tipo de revista sem um público definido, difícil de achar anunciantes. Do ponto de vista comercial, seria melhor ter feito uma publicação para um público-alvo como anões albinos ou cosmonautas drusos (Chacal, 2010, p. 179).

A ideia de fazer uma revista nasceu entre amigos e, ironicamente, pode ter-se findado justamente por isso. Não que seja um ponto negativo uma revista poético-cultural não ter tido um público-alvo definido, não ter tido êxito comercial, pois como já tinha sido constatado anteriormente por Torquato Neto e Waly Salomão, periódicos literários e culturais têm vida curta - tanto que decidiram fazer uma edição única de Navilouca. O maior problema talvez tenha sido o número decrescente de artistas no conselho editorial da revista: no primeiro número do periódico, 18 pessoas faziam parte do conselho, seguidas de quinze na segunda edição, 13 na terceira, 12 na quarta e apenas 4 na quinta e última edição. A falta de anunciantes poderia até ser previsível para um periódico poético-cultural, mas talvez a desistência dos próprios idealizadores é que não estava prevista. No quinto fascículo, na antepenúltima página, até o certificado de enquadramento do projeto da revista perante à lei de incentivo da cultura foi exposto para pedido de apoio de anunciantes e/ou financiadores. Infelizmente, parece não ter surtido grandes efeitos: aquele acabou sendo o último número da revista.

Última edição à parte, pelo menos por enquanto, é na apresentação da revista O Carioca, em seu primeiro número, de 1995, que Chacal elucida como a ideia de fazer o periódico surgiu, numa saudação à cidade, aos artistas, aos amigos e ao RioArte.

o carioca nasceu num futivoley noturno na praia de ipanema no último verão. a rapaziada ali feliz, comemorando uma nova luz. o rio é uma cidade extraordinária. para quem tem olhos de ver. violência é mal do tempo. alegria, nosso dom. o carioca nasceu entre amigos, amigas, cerveja e verão. pode ser um bloco de carnaval, um time de futebol, uma banda de rock, um trem de doido. é tudo isso impresso, expresso para você. o carioca saúda o rioarte, artistas do rio s.a. e conta com todos eles para que a bola dessa cidade role cada vez mais redonda (O Carioca, 1995, p. 3).

Mas a história não começou apenas com o futevôlei na praia. Ainda mais porque não se tratava de qualquer praia, tratava-se de Ipanema, Posto 9: ponto de encontro entre amigos, amigos de amigos, cerveja na mão, bola no pé e, com dunas da Gal ou não, encontros lisérgicos, de curtição, mas também de trabalho. O Posto 9 foi, desde os anos 1970, para Chacal, um lugar dominante. Era lá, segundo suas próprias memórias, no livro Posto 9, edição da coleção Cantos do Rio financiada pelo RioArte, que ficava sabendo sobre uma nova oportunidade de trabalho, era onde conhecia os novos artistas e onde surgiam ideias para novos projetos.

O financiamento do RioArte nos projetos de Chacal (CEP 20.000, O Carioca e Posto 9) não parece uma coincidência, mas a continuidade de um trabalho em que o RioArte mantinha equipes de profissionais, sempre com o objetivo de informar e divulgar temas relacionados à Cultura Carioca. Efetuava também apoio e incentivo permanente à pesquisa e à divulgação da produção de produtos culturais de qualidade para a cidade do Rio de Janeiro, como por exemplo, através do Programa de Bolsas, cujos artistas selecionados, recebem bolsas mensais, que viabilizam a produção de livros, publicações, CDs, peças de teatro, eventos culturais, exposições e interferências urbanas, que falam da nossa gente e da nossa realidade (TCMRJ, 2003, p. 3).

No entanto, o RioArte foi extinto em 2006 pelo então prefeito do Rio de Janeiro Cesar Maia, afirmando que o Decreto $n^{\circ} 26.210$, baseado na Lei $n^{\circ} 237 / 1982$, que fazia com que o RioArte passasse de autarquia para sub-secretaria, era inválido. O projeto CEP 20.000, porém, continuou sendo financiado pela Prefeitura do Rio de Janeiro.

Para além das questões de financiamento, que vieram a posteriori, o Posto 9 era o lugar que o grupo Nuvem Cigana mais frequentava e foi lá também que a ideia de fazer $O$ Carioca surgiu. Estavam entre o futevôlei e o bar do Cervantes, pelo menos seis dos colaboradores mais fiéis: Fernanda Abreu, Barrão, Fausto Fawcett, Laufer, Raul Mourão e Cafi. Além das idas ao Posto 9, há cinco anos já aconteciam mensalmente os encontros no CEP 20.000 (Centro de Experimentação 
Poética), no Espaço Cultural Sérgio Porto. Diferente de O Carioca, a ideia de fazer o CEP surgiu no Baixo Gávea a partir de uma conversa entre Chacal, Guilherme Zarvos e Carlos Emílio. A vontade de montar o projeto veio com a lembrança do Terças Poéticas ${ }^{5}$ e da repercussão que o evento causara nos jovens artistas ao assistirem os mais consagrados nomes da poesia e da crítica de perto. Editor do jornal do RioArte, Carlos Emílio sugeriu que a ideia fosse apresentada a Tertuliano dos Passos, presidente do órgão que já tinha trabalhado com Chacal anteriormente. Foi então que mais um projeto de Chacal foi financiado pelo RioArte. No caso do CEP 20.000, o que o RioArte disponibilizava era a parte de infra-estrutura para o projeto acontecer, ou seja, o Espaço Cultural Sérgio Porto. Desde agosto de 1990, então, mensalmente, o CEP 20.000 acontece e hoje já possui mais de 20 anos com a proposta de fazer uma espécie de sarau performático, no qual poesia, música e teatro estariam entrelaçados num espaço cultural onde todos pudessem expor sua arte. CEP, que antes de ser Centro de Experimentação Poética significa Código de Endereçamento Postal, marca seu recorte quando carrega em seu nome o número da cidade do Rio de Janeiro: 20.000. O número também relembra a Navilouca, pois a revista setentista trazia o código impresso em seu editorial, marcando o lugar onde surgia, a capital fluminense. ${ }^{6}$

Tanto a revista O Carioca quanto o CEP 20.000 podem ser entendidos como partes de um mesmo projeto: (des)organizam os artistas e poetas já consagrados com aqueles que estão apenas começando em um espaço de livre acesso para que possam dialogar entre si e movimentar, ou ainda, não deixar parar, a produção cultural contemporânea carioca, já que há um grande número de colaboradores e editores de diferentes grupos e gerações. $\mathrm{O}$ grande feito inédito do CEP 20.000 é a continuidade do projeto, que perdura durante os diferentes governos da cidade. Ao completar 19 anos de CEP, Chacal abre o evento afirmando a importância do projeto e de sua continuidade.

E o que a gente sempre fez aqui nesses 19 anos foi dar espaço para a poesia, seja ela em forma de música, em forma de performance, em forma de vídeo, teatro, cenas. Sempre foi isso, é um mistério. Mistério talvez seja permanecer dezenove anos em funcionamento numa cidade um tanto cariada de projetos, e numa época em que tudo muda rapidamente. O único mistério é que eles me pagam pra fazer o CEP 20.000 e eu preciso dessa grana. Então, não há mistério. Eu preciso disso, então é com muito prazer que eu venho aqui todo mês, há 19 anos pra dar sequência a essa farandula, essa ciranda interminável de poetas e artistas. E isso me agrada muito (Chacal apud Gomes, 2012). ${ }^{7}$

Além da infraestrutura que o RioArte disponibilizava ao CEP 20.000, o órgão também apoiava o CEP 20.000 Quadrinhos, revista confeccionada por Guilherme Zarvos e Michel Melamed. Quando extinta, o veículo impresso do grande grupo que participava do CEP veio a ser $O$ Carioca. Constatada a questão de que poesia não vende, depois de algumas tentativas ainda na década de 1970 - na era dos mimeógrafos - era a hora e a vez do poeta desbravar os editais das leis de incentivo à cultura. A relação Chacal-RioArte provou muito bem isso.

O que tanto a revista $O$ Carioca quanto o CEP 20.000 têm de mais interessante é o fato de que ambos os projetos promovem uma abertura de espaço para novos poetas e artistas da cidade do Rio de Janeiro, sendo Chacal o principal agitador dessa estrutura. Nomes como a poeta e filósofa Viviane Mosé que, em 1995 - no primeiro número da revista O Carioca - só havia publicado um livro, o Escritos, de 1990. Ou ainda, poetas e escritores que estavam sendo publicados pela editora 7Letras, como Sérgio Natureza e Vivien Kogut, o que, de certa forma, identifica uma parte dos colaboradores: aqueles que fazem parte da renovação dessa literatura por parte do editor Carlito Azevedo, que era simultaneamente editor da revista Inimigo Rumor, de poesia, e da revista Ficções,

\footnotetext{
${ }^{5}$ Este era um evento que acontecia no prédio do curso de Comunicação da UFRJ, na Urca, na década de 1980, que misturava palestras e debates de críticos e poetas consagrados como Heloísa Buarque de Hollanda, Antônio Houaiss e João Cabral de Melo Neto, a performances de poetas e músicos jovens, numa espécie junção entre o meio acadêmico e o meio artístico.

${ }^{6}$ Para mais informações sobre a revista Navilouca e a participação de Chacal na revista, ler: "A nau dos Tropicalistas: Chacal, poesia errante", de Renata Gonçalves Gomes (2016).

${ }^{7}$ Esse excerto faz parte da fala que Chacal fez na abertura do CEP 20.000 que aconteceu em agosto de 2009. O evento foi registrado em vídeo pela autora e está disponível em formato DVD em anexo à dissertação Meu nome é Chacal: a moldura e a poesia do poeta em periódicos (Gomes, 2012).
} 
de prosa. Há também os poetas e artistas colaboradores da revista e que participavam - a maioria ainda participa - do CEP 20.000 como: Guilherme Levi, Fausto Fawcett, Tavinho Paes, Pedro Luis (e a parede), Guilherme Zarvos, Casé Pecini e Michel Melamed. Outro grupo identificado na revista é o dos poetas da década de 1970, sejam do grupo Nuvem Cigana, como é o caso de Bernardo Vilhena, Raul Mourão, Ronaldo Bastos, Charles (Peixoto) e Cafi, ou ainda poetas bastante consagrados como Francisco Alvim, Eudoro Augusto, Waly Salomão, Torquato Neto, Nicolas Behr, Paulo Leminski, Alice Ruiz, Zuca Sardana e Armando Freitas Filho. Além de poetas como Carlito Azevedo, Antonio Cícero, Arnaldo Antunes e Paulo Henriques Britto, que, nos dias atuais, são alguns dos grandes poetas em atividade no Brasil.

Com toda a variedade de poetas de diferentes estéticas, poéticas, décadas e grupos, $O$ Carioca não assume uma linha estética padrão, diferente do que Inimigo Rumor e Azougue irão sugerir como padrão editorial. ${ }^{8}$ A revista $O$ Carioca, portanto, viabiliza uma abertura para poetas e artistas de várias poéticas e de vários grupos: o ecletismo, aqui, é marca, é mistura, é lançar postumamente um poema inédito de Torquato Neto, Cazuza e Renato Russo, mas não deixar de lançá-los entre uma página dedicada a Waly Salomão, outra à banda Farofa Carioca e assim por diante. É um estar entre os poetas e artistas já consagrados com aqueles que configuram uma suposta nova cena.

No CEP 20.000 a abertura é ainda maior, visto que o espaço é literalmente aberto a qualquer poeta que queira participar, pagando uma pequena taxa cobrada na entrada, e expor seu poema, música, vídeo ou performance para o grupo que está assistindo. $\mathrm{O}$ dinamismo que o CEP 20.000 traduz está representado em exemplos como a participação do jovem poeta Pedro Henrique Medrado, que foi ao CEP de agosto de 2010 para se apresentar sem ter tido contato prévio com qualquer pessoa da produção. Quando Chacal, entre uma apresentação e outra, perguntou se alguém queria ir ao palco falar algo, Pedro Henrique saiu da plateia e se juntou a Chacal no palco. E no fim do CEP, Pedro Henrique ainda distribuiu seu zine - o irmão mais novo do mimeografado - para as pessoas que acabava de conhecer no Espaço Sérgio Porto.

No CEP 20.000 é possível encontrar alguns dos poetas selecionados por Heloísa Buarque de Hollanda em sua mais recente antologia, o ENTER: antologia digital, que reúne poetas dos anos 2000 que utilizam a internet como meio de divulgação e publicação de seus poemas. ${ }^{9} \mathrm{O}$ grupo Sete Novos, composto por Mariano Marovatto, Domingos Guimaraens e Augusto Guimaraens, participou diversas vezes do CEP e junto com Chacal, participava ativamente das "brechas" entre uma apresentação e outra. A jovem poeta Alice Sant'anna, que também está na antologia de Heloísa, não só participou em alguns saraus do $C E P$, como trabalhou com Chacal na revisão de seu último livro, Uma história à margem, pela 7Letras, editora que lançou seu primeiro livro, o Dobradura (2008). O jornal que Alice edita junto com outros jovens poetas, o Plástico Bolha, teve colaboração de Chacal em seu quarto ano, no número 27, onde o poeta carioca publica oito poemas: os já antes publicados em livros "Bem-vinda", em Belvedere, "vento vadio", em Olhos vermelhos, "prezado cidadão", em Muito prazer, Ricardo, "mirabel" e "ópera dos pássaros", em A vida é curta pra ser pequena, e mais três poemas inéditos "deixa pra lá", "drama familiar" e "e as couves". ${ }^{10}$ Alice dedica seu livro Dobraduras a seus pais e seus padrinhos - leia-se, padrinhos

\footnotetext{
${ }^{8}$ De qualquer forma, Chacal teve uma colaboração isolada em cada revista. Na revista Inimigo Rumor, ano 1, n. 17, com o poema "Sentinela", e na revista Azougue, n. 18, 2003, com poemas do livro Preço da passagem, em comemoração aos 31 anos do personagem Orlando Tacapau.

${ }^{9}$ Apesar de manter dois blogs online, seu primeiro, o Chacalog (http://chacalog.zip. net/), que tem o último texto publicado em 20 de fevereiro de 2011, e o Uma história à margem (http://umahistoriaamargem.blogspot.com/), a propósito de sua biografia homônima, com último texto publicado em 14 de julho de 2011, o poeta parece ter abandonado os blogs e a postagem de textos e poemas inéditos ou já publicados anteriormente no ambiente virtual.

${ }^{10}$ Na edição do mês de janeiro de 2012, ano 7, n. 30, distribuída no formato papel, há um poema inédito de Chacal, com o título de "pedras portuguesas", na seção "Dobradinhas", escrita por Alice Sant'anna e, nesta edição, em conjunto com o poeta carioca, com ilustração de Raissa Degoes. Esse poema de Chacal foi posteriormente publicado em seu livro Murundum (2012), pela Cia. das Letras. Na seção do Plástico Bolha em que foi lançado, normalmente, são publicados dois poemas que, de alguma forma, dialogam, se (des)dobram pelo tema, pelo ritmo, pela forma, etc. Não parece ter sido diferente nesta edição, seguem os poemas: "pedras pedros pedradas/ pedros pedras perdidas/ as pedras por onde pisas/ estão felizes da vida// felizes porque circulas/ entre eleas encantada/ enquanto eu aqui fico/ nesse tilintar sem fim// no meu descalçado jardim/ queria que aqui viesses/ passear dentro de mim// e depois
} 
literários -, Armando (Freitas Filho), Pedrinho (Lage) e, veja!, Chacal, sintoma de uma relação estreita do poeta com a nova produção carioca. Sérgio Vaz, poeta paulista vinculado ao grupo Coperifa, dito de periferia, não só participou de algumas experimentações poéticas no CEP, como também de uma mesa-redonda em Florianópolis, junto com Chacal. ${ }^{11}$

É interessante pensar, então, a partir da revista O Carioca e do CEP 20.000, a posição de Chacal perante a contemporaneidade, essa posição frente a seu tempo e ao seu espaço. Segundo o filósofo Giorgio Agamben (2009), o contemporâneo é aquele que ao mesmo tempo consegue aderir-se a seu próprio tempo, mas sabe dele também se distanciar, é um equilíbrio entre esse afastar-se e aproximar-se de seu tempo. Em relação ao poeta, lendo Osip Mandel'stam, Agamben afirma que é com a vida que o poeta deve pagar a sua contemporaneidade, mantendo fixo o olhar nos olhos de seu tempo: o tempo da vida do indivíduo (Agamben, 2009, p. 60). É no poema "tempo", do livro A vida é curta pra ser pequena (2002), que Chacal apresenta o pensamento da contemporaneidade que trabalhara anteriormente através da O Carioca e do CEP 20.000.

no início era o começo.

o depois veio vindo devagar.

o antes veio depois do depois.

só quando este se estabeleceu.

no princípio era o agora.

isso demorou.

até que tudo virou

antes e depois.

então numa revolução peluda

o agora voltou ao trono.

antes e depois viraram

falta do que fazer.

e tanto fizeram

que o agora virou tudo

e o tudo, nada.

de volta ao princípio,

o agora agora congelou.

o antes fica pra depois (Chacal, 2002, p. 77).

Segundo Agamben, o equilíbrio entre a nostalgia e a atualidade e entre o anacronismo e o deslocamento faz com que o poeta seja um contemporâneo. O poema joga com as idas e vindas do antes e do depois, do agora que vira tudo e o que era tudo nada. O tempo é seu, e ele não fica preso ao tempo cronológico. E é no jogo entre nostalgia e atualidade que a revista O Carioca mais se enquadra: além de buscar uma inserção dos novos poetas e artistas no meio cultural carioca, o periódico também compactua com a ideia de relembrar aqueles movimentos culturais que tiveram notoriedade nacional e pelos quais a capital fluminense teve influência. É o caso da seção "Memórias Contemporâneas", que aparece nos quatro primeiros números da revista. Definida por Chacal, essa seção foi dedicada:

[...] a tudo que tiver a ver com o passado recente e o futuro remoto dessa cidade. Espaço para o que houve de importante para a cultura do Rio. Coisas que, por falta de registro, caíram no esquecimento. Ou quase. Coisas que devem servir no mínimo, como diz o antropófago Waly Salomão, de alimento para as novas gerações (O Carioca, 1995, p. 12).

\footnotetext{
de tremoço e cerveja/ rolarmos nus indolentes/ pelas pedras portuguesas", de Chacal; e de Alice Sant'anna intitulado "English breakfast": "é curioso, o chá escurece/ os dentes mas por outro lado/ a água não os clareia, ela// segura a haste da caneca/ como se daquilo dependesse a vida/ as flores pintadas na caneca// toma chá pelando mesmo no verão, pela/ janela não chega o cheiro de sal nem/ as quinas das pedras portuguesas". O jornal Plástico Bolha, de certa forma, compactua com os pressupostos e a ideologia de $O$ Carioca e CEP 20.000, já que publica e lança muitos poetas e escritores fluminenses. Atualmente, o jornal vem sofrendo com a falta de recursos financeiros para a continuação da periodicidade.

${ }^{11}$ A mesa-redonda Poesia Marginal e de Periferia, composta por Chacal (RJ), Sérgio Vaz e Cooperifa (SP), Kim Isaac (SC) e Demétrio Panarotto (SC), aconteceu no dia 24 de abril de 2009, às 20 horas, no Teatro SESC Prainha, em Florianópolis.
} 
Como o texto citado sugere, não se tem muitos registros além de poucas fotografias da época, portanto, a seção é toda escrita através de depoimentos, memórias de uma época recente que não se deve deixar desaparecer, deve ser passada adiante: é uma seção que fica no limiar da memória com a atualidade. Dos quatro textos, dois foram escritos pelo próprio Chacal. Na revista número um, Chacal relembra os blocos de carnaval de rua do Rio de Janeiro na década de 1970 como o Suvaco de Cristo e como o Charme da Simpatia - bloco do grupo Nuvem Cigana. Em outro texto para a seção, na revista número quatro, Chacal relembra uma época mais recente, a do Baixo Gávea, bairro onde foi morar em meados da década de 1980. Os outros relatos, em forma de memórias nostálgicas, são de Hamilton Vaz Pereira, número dois da revista, em que relembra a época do grupo teatral Asdrubal Trouxe o Trombone com um fragmento de peça com duas das principais personagens: Gilda e Julita; e José Simão, na revista número três, que relembra as famosas Dunas da Gal da década de 1970 em Ipanema. Sendo assim, entre a nostalgia e a novidade, O Carioca perpassa questões da contemporaneidade, do tempo, e do ser contemporâneo.

Mesmo que seja possível ter várias leituras da revista, é interessante pensar que tudo nela está diretamente vinculado a uma imagem da cidade do Rio de Janeiro, a uma construção de ideia sobre a cidade. No primeiro número, na contracapa, há um poema de Chacal inédito que na revista se apresenta sem título, mas que no livro $A$ vida é curta pra ser pequena foi publicado sob o título de "rio" e possui uma forma distinta - ilustrado com uma fotografia do cineasta e fotógrafo João Vargas (Penna) de uma das praias da capital fluminense. O poema é uma ode ao Rio de Janeiro, numa personificação da cidade como musa inspiradora. Com referência direta ao "Primeiro caderno de poesia do aluno Oswald de Andrade", o rio, Rio de Janeiro, se traduz em amor e humor através da fruição do olhar e sentir a cidade: "água na boca é a guanabara".

o rio é basicamente o mar o mar e o amor amor e mar atlanticamente amar]

o rio é basicamente o riso amor humor humor amor instintivamente gozar]

água na boca é a guanabara o arpoador é jóia rara

pelas curvas desse rio ninguém vai morrer de frio

porque é só se espreguiçar no sol detrás do mar (O Carioca, 1995, p. 2).

O Rio de Janeiro, como musa inspiradora, é uma construção feita em praticamente todas as seções da revista, praticamente personificando a cidade à moda antiga, como os românticos faziam com suas musas. Sobre os poetas românticos Manuel Bandeira, em seu livro Apresentação da poesia brasileira, diz:

[...] os Poetas brasileiros se deixaram levar pelos seus cânticos e olvidaram as simples imagens que uma natureza virgem com tanta profusão lhes oferecia. [...] A poesia romântica enche o século XIX, de 36 até os primeiros anos da década de 80, renovando-se através das gerações, não na forma - vocabulário, sintaxe, métrica - a que se manteve sensivelmente fiel, mas nos temas, no sentimento e no tom (Bandeira, 2009, p. 43-44).

Então, é possível voltarmos a ler a poesia de Chacal, neste caso, como romântica, como já disseram Silviano Santiago, Cacaso e Benedito Nunes a propósito dos poemas iniciais do poeta carioca. A cidade, ou a musa, passa por todas as seções da revista e faz com que o tempo-espaço seja importante para a construção de um conceito sobre o contemporâneo carioca. Neste sentido, cabe lembrar o objetivo que o principal financiador da revista, o RioArte, tinha: o de promover a cultura local carioca. Desde o nome, passando pelas colaborações e seções da revista até chegar ao principal financiador do periódico, $O$ Carioca transborda a tentativa de definir e representar uma identidade cultural da cidade, se é que ela existe.

Nas colaborações relacionadas às artes plásticas, muitas fotografias buscam um olhar do Rio de Janeiro, como a capa da revista número dois, com fotografia de Belisário Franca. As capas das revistas, aliás, são as páginas coloridas de $O$ Carioca, que tem todas as suas edições com as páginas em preto-e-branco, o que para as artes plásticas é um diferencial.

Chacal ainda colabora na revista com mais um poema, "o beijo", na época inédito e hoje também lançado no livro A vida é curta pra ser pequena. O poema "o beijo", publicado na revista 
número dois, aparece sem título - assim como "rio" -, mas já dedicado a Simone Couto. ${ }^{12}$ Em alguns poemas, percebe-se que o processo de escritura é contínuo, mesmo depois de publicados, visto que há mudanças em relação ao acréscimo dos títulos ou a suas formas. todo mundo precisa de beijo o ascensorista a vitrinista

a judoca o playboy o zagueiro o bombeiro o hidrante o hidrante precisa também de cuidados água farta analgésicos e dinheiro

todo mundo precisa de dinheiro o maracanã o pavilhão são cristóvão o cristo a pedra da gávea os dois irmãos

quem não precisa de dinheiro? todo mundo precisa de beijo (O Carioca, 1996a, p. 14).

As imagens desse poema, que chamarei de "o beijo" por assim ter sido intitulado posteriormente, são extremamente vinculadas à capital fluminense, quase que beirando o clichê dos cartões postais: maracanã, pedra da gávea, cristo redentor. A forma do poema chama atenção pela ausência de pontuação entre uma imagem e outra. Chacal utiliza o espaçamento triplo para dar a pausa necessária, em vez do uso da vírgula, trabalhando a dispersão das palavras e das imagens do poema. O que posteriormente, no livro A vida é curta pra ser pequena, se perde, não há vírgulas, mas também não há espaçamento longo entre as palavras.

Chacal ainda publica outro poema que faz referência à antropofagia de Oswald de Andrade. Esse poema, sem título, é publicado ao lado de uma fotografia de Walter Carvalho que serve de ilustração para o poema. Na foto, em preto e branco, um rapaz aparece sorridente, sentado à mesa com um prato bastante farto em sua frente. E o poema de Chacal, na página ao lado, dizendo:

comer é bom. comer faz bem. quero comer você também. comer com os dentes. comer com a mão. mastigação. deglutição. nhac. nhac. nhac. nhac. abocanhar. rasgar. solver. de cada naco, sugar o sumo. de cada nada, sorver o tudo. para só aí, só então, poder parir. comer é bom. comer faz bem. o coelho da comadre, perereca da vizinha. a anca branca. a rosa rubra. comer tudo que à mão se oferece. comer com garra. comer com fome. comer pagão. comer até saciar. se empapuçar. se empanturrar. comer é bom. comer faz bem. tudo que ao espírito se endereça. a ode triunfal de pessoa. uma faco só lâmina de cabral. nasce o poema de gullar. salt of the earth dos stones. like a rolling stone do dylan. sinal fechado do paulinho. estácio, eu e você de melodia. lígia de tom. um rir. rir. com luís fernando. chorar com cartola. dançar com fernanda. em si se ensimesmar. comer é bom. comer faz bem. vamos fazer nenem nenem (O Carioca, 1996b, p. 29).

A forma desse poema, publicado na revista $O$ Carioca, deixa a versificação de lado para trazer uma estrutura mais próxima da prosa. O poema se espalha pela página em letras brancas, numa contraposição com o fundo preto da folha. Assim como no poema "rio" e no poema "o beijo", a intenção parece ser (des)estruturar o poema, deixá-lo espalhado pelas largas páginas da revista, dispersá-lo. Ainda, a metalinguagem que este poema traz à tona é oswaldiana, é antropofágica. E como poucas vezes antes, Chacal - o poeta que cria a moldura vinculada a uma poesia que não pertence à biblioteca - citando, comendo, João Cabral de Melo Neto, Fernando Pessoa e Ferreira Gullar, poetas que jamais pertenceram a sua (dita ausente) biblioteca. Além das referências musicais sempre muito presentes em sua poética, como Bob Dylan, Rolling Stones, Cartola, Tom Jobim, Fernanda Abreu e Luís Melodia.

\footnotetext{
${ }^{12}$ Este poema também foi publicado sem título no Suplemento Literário de Minas, em janeiro de 1996, com versão diferente da publicada na revista $O$ Carioca e também no livro $A$ vida é curta pra ser pequena.
} 
Sendo assim, é possível pensar tanto a revista O Carioca quanto o projeto CEP 20.000 como partes do que Paulo Henriques Britto apontou, na revista Sibila (2006), como o novo cenário da literatura contemporânea: aqueles que ainda articulam poesia e vida (Britto, 2006, p. 74). Mas não apenas isso, os dois projetos de Chacal participam de uma dispersão da poesia e dos poetas, em que não há exatamente um grupo que pensa uma única estética, mas há, ao contrário, uma grande produção, volumosa, de bons poetas sem, necessariamente, serem os grandes poetas da literatura brasileira, como já afirmou Britto (2006). Dessa forma, é possível explicar a disparidade de colaboradores e de editores, além de autores citados, na revista $O$ Carioca, pensando tanto a revista quanto o projeto CEP 20.000 como sintomas do cenário da poesia brasileira do fim do século XX e início do século XXI, e não apenas da poesia carioca.

\section{Referências}

AGAMBEN, Giorgio (2009). O que é o contemporâneo? E outros ensaios. Chapecó: Argos.

BANDEIRA, Manuel (2009). Apresentação da poesia brasileira. São Paulo: Cosac Naify.

BRITTO, Paulo Henriques (2006). O lugar do poeta e da poesia hoje. Sibila, São Paulo, n. 10, p. 70-77, nov.

CHACAL (2002). A vida é curta pra ser pequena. Rio de Janeiro: Frente.

CHACAL (2003). 31 Anos de Orlando Tacapau (Preço da passagem 1972/2003). Azougue, n. 8, abril, p. 78-83.

CHACAL (2010). Uma história à margem. Rio de Janeiro: 7 Letras.

GOMES, Renata Gonçalves (2012). Meu nome é Chacal: a moldura e a poesia do poeta em periódicos. Dissertação (Mestrado em Literatura) - Centro de Comunicação e Expressão, Universidade Federal de Santa Catarina, Florianópolis. Disponível em: https:/ / bit.ly/2PGt6SN.

GOMES, Renata Gonçalves (2015). Almanaque Biotônico Vitalidade e as artimanhas: a contracultura engarrafada no Brasil. Revista do Arquivo Geral da Cidade do Rio de Janeiro, Rio de Janeiro, n. 9, p. 399-410.

O CARIOCA (1995). n. 1, Rio de Janeiro.

O CARIOCA (1996a). n. 2, Rio de Janeiro.

O CARIOCA (1996b). n. 3, Rio de Janeiro.

O CARIOCA (1997). n. 4, Rio de Janeiro.

O CARIOCA (1998). n. 5, Rio de Janeiro.

SANT'ANNA, Alice (2008). Dobraduras. Rio de Janeiro: 7 Letras.

TCMRJ - Tribunal de Contas do Município do Rio de Janeiro. Inspeção Rioarte e Fundação Rio. Rio de Janeiro, 2003. On-line. Disponível em: http://www.tcm.rj.gov.br/Noticias/1056/RIOARTE.pdf

ZARVOS, Guilherme (2009). Branco sobre branco: Centro de Experimentação Poética 20.000: Centro de Experimentação Pensamento: uma possível rota. 1a edição. São Paulo: Ateliê; Rio de Janeiro: Nonoar. 